\title{
1 Expert endorsement and the legitimacy of public 2 policy. Evidence from Covid19 mitigation 3 strategies.
}

Francesco Bogliacino ${ }^{1,2, X}$, Camilo Gómez, ${ }^{1,2}$, Felipe Montealegre ${ }^{1,2}$, Rafael Charris ${ }^{2}$, Cristiano Codagnone ${ }^{3,45}$

${ }^{1}$ Universidad Nacional de Colombia

${ }^{2}$ Centro de Investigaciones para el Desarrollo

${ }^{3}$ Università degli studi di Milano

${ }^{4}$ Open Evidence Research

${ }^{5}$ Universitat Oberta de Catalunya

X Corresponding author. Address for correspondence: Facultad de Ciencias Económicas, Universidad Nacional de Colombia, Kr 30, No 45-03,Bogotá (Colombia),fbogliacino@unal.edu.co

\section{Abstract}

During a pandemic, the government requires active compliance by citizens. While these demands can be enforced with rewards and punishments, legitimacy allows the government to achieve the same results with greater cost effectiveness. In this article, we measure revealed legitimacy through support of three potential mitigation strategies against Covid19, when they are defended using expert endorsement, consultation by civil society, and mediation between opposing interests. We elicit approval of the supporting arguments and of the communication strategy. Our methodological choice was to randomly assign participants to either a nonconflicting priming or to one that emphasizes the risks involved, (e.g. connection between health and economy, uncertainty, and economic costs). The data come from an online experiment we conducted as part of a longitudinal study of several countries. The countries included are Italy, Spain, and the United Kingdom. The results show that the support of experts in noncontroversial domains is preferred (consensus of value, low uncertainty, diffuse rents). Contrary to our hypotheses, we found that citizen deliberation is not preferred under high epistemic uncertainty, and mediation is either indifferent or not preferred under conflict of value and conflict of interest.

Keywords: Covid19; legitimacy; evidence-based policy; tracing; testing; social isolation JEL Classification: D78; I18; J18; C99; D91

Words count: 9660 (from title to references) 
1 Acknowledgment: Funding has been provided by Open Evidence and BDI-Schlesinger

2 Group. We thank Noe Andreu for help with the programming and the data collection and

3 Douglas Rodríguez who helped as RA. We appreciate comments from seminars at Banco de la

4 Republica and the virtual seminar on Covid19 organized by EAFIT. The authors declare no

5 conflict of interest.

6 This article has been accepted for publication in Journal of Risk Research, published by 7 Taylor \& Francis. The current version is the Author Original Manuscript, pre-peer review. 


\section{Introduction}

2 During a pandemic, the government requires citizens to approve the decisions that are made,

3 but also require them to comply with the recommended behavior. Although government can

4 enforce decisions via reward and punishment, this is not cost effective: legitimacy allows

5 government to obtain the same results with much less resources. Legitimacy holds when citizens

6 believe that the decision taken is the right one, and the government is justified to having adopted

7 it. In democratic regimes, legitimacy is acquired via procedural fairness. However, pandemic is a

8 contingency where the government makes decisions via urgency decrees and the balance

9 between legislative and executive power is less in equilibrium. Substantive legitimacy becomes

10 thus more important. The way in which a government can acquire substantive legitimacy has a

11 lot to do with how it communicates and justifies its decisions.

12 One way to justify a decision is via expert endorsement. This has been criticized as a distortion

13 of Evidence Based Policy (where experts' opinion replace hard facts, Strassheim and Kattunen,

14 2014), arguing instead that citizen mobilization should provide the necessary arguments to

15 support the decisions (Carrozza, 2014), especially when the stakes at hand increase, as for global

16 warming and other societal challenges. Other scholars argue that recognizing biases and putting

17 partial visions in conflict is actually a better way to let the real evidence reach the citizens, as in

18 the famous argument in favor of adversarial penal system (Bogliacino et al. 2019). Whether

19 expert endorsement is better than citizen consultation or negotiated conflict among opposing

20 groups depends on the framing of the debate for the specific public policy. In particular, three

21 dimensions are relevant, i.e. how uncertain is the domain, how conflictive it is in terms of values, 22 and how large are the interests at stake. 
In this article, we use the Covid19 crisis and three proposals of mitigation strategies to elicit

2 approval of supporting arguments and communication strategy, namely expert endorsement, 3 citizen mobilization, and negotiation and mediation, in order to measure perceived legitimacy.

4 Our key methodological choice was to randomly allocate participants to either a non-conflictive

5 priming or to one that stresses the stakes at hand, such as the strong connection between health

6 and economics, the radical uncertainty surrounding many aspects of the pandemics, and the

7 potential risks in terms of reduction of freedom and rights by increased governmental control.

8 The policy options were a softened version of the lockdown (capturing the baseline conditions

9 in the three countries at the moment of data gathering from the $10^{\text {th }}$ to the $20^{\text {th }}$ of May), a trace

10 and isolate policy via smartphone app, and a test and isolate policy via serologic tests. The

11 arguments asked to be rated where an appeal to experts, a deliberative argument based on 12 consultation of the public opinion on the matter, and a "negotiation" stance claiming that the 13 decision has been taken after mediating different groups. Data comes from a split ballot we 14 conducted as part of a multi-country longitudinal study (Bogliacino et al. 2020b), aimed at 15 following a random sample of citizens aged 18-75 years old over a month, during the lockdown.

16 Countries included are Italy, Spain, and UK, which have been seriously hit by the disease.

17 The main contribution of this article is to provide a rigorous assessment of alternative framing 18 and communication strategies for adoption of policies. Additionally, by contextualizing this 19 problem in terms of the alternative mitigation strategies for Covid19, this article provides 20 valuable insights for policymakers. Lastly, this article contributes to the key debate on the 21 complicate relationship between evidence and policy, and in particular on the opportunities and 22 risks of expert endorsement. 
As predicted in our pre-registered hypotheses, expert endorsement is preferred under non

2 contested domains (value consensus, low uncertainty, diffused rents). Contrary to our

3 hypotheses, citizen deliberation is not preferred under high epistemic uncertainty, and mediation

4 is either indifferent or non-preferred under value conflict and conflict of interests. In terms of

5 policy options, there is not a strong support for tracing and testing with respect to baseline policy

6 of social isolation.

7 The article proceeds as follows. Section 2 presents the theoretical framework on legitimacy,

8 followed by Section 3 that explains in detail the design. We then present the results in Section 4

9 and conclude in Section 5. The experimental protocol is in the Annex.

11 2. Legitimacy, communication, and welfare

12 In modern advanced societies, the State has two routes to achieve its objectives in terms of 13 collective outcomes. As the owner of the monopoly of power, it can threaten punishment to 14 dissuade a behavior, or promise rewards to induce it. This is the standard way. Although 15 effective, this is expensive, because it requires the diversion of resources from other means to 16 enforcement. An alternative is using legitimacy to obtain deference, i.e. lack of opposition to the 17 decisions taken, and active behavioral change in support of the measures (Tyler, 2006). In other 18 words, citizens are normally willing to conform to a rule of conduct not only because of fear or 19 benevolence, but also because they do not want to betray expectations which are considered 20 legitimate (Bicchieri, 2006). According to Weber (1968), internal motivations are as important as 21 sanctions and rewards.

22 Legitimacy is a belief over the character of an authority as righteous (Tyler, 2006). Legitimacy 23 causes trust: trust is the willingness to put resources at the disposal of another party (Fehr, 2009). 
1 Legitimate authorities are thus able to take measures and implement policies, because via trust,

2 citizens are willing to comply. This is shown in the research over institutions such as the police

3 (Tyler, 2001, 2011). However, it is particularly important for the case of companies or

4 organizations, where deference is not enough, and the authority requires active involvement by

5 employees. The role of norms, in particular norms of fairness, has long been stressed by the

6 economic literature: it has been argued that certain rules of conduct from the managers induce

7 extra effort from the side of the workers, beyond what can be enforceable via the definition of

8 the contractual terms (Akerlof, 1980; Fehr and Gachter, 1998; 2000; Fehr et al. 1998).

9 In the domain of public policy, legitimacy is acquired procedurally (Thibaut \& Walker 1975),

10 via the definition of a correct institutional process. However, policies are defined by a dimension

11 which is particularly relevant: time (Wallner, 2008). The timing of the policy requires to achieve

12 a reservoir of support which makes it possible to survive through the cycle of approval and

13 implementation. Given the pressure of the time constraint, authorities are required to achieve

14 also substantive legitimacy. This can occur in various ways; the more efficacious being via a

15 framing of the policy as in agreement with the interests of the stakeholders (in other words,

16 convincing on the bounty of the policy), or generating the correct emotive appeal for the agenda.

17 Nowadays, a widely used argument is evidence: a strategy of legitimation based on hard facts

18 from an epistemic authority. This is usually dubbed as evidence-based policy (EBP) or what works

19 approach (Cartwright and Hardie, 2012; Gueron, 2017). A discussion of EBP is out of the scope

20 of this article. Suffice to say that it is a reappraisal of the methodological approach put forth by

21 Roland Cambpell in his famous Reforms as experiments manifesto (Cambpell, 1969), although

22 developed into a quite different framework. Whereas the Campbell's objective was the tradeoff

23 between increasing democratization and social justice and maintenance of the open society

24 (under the threat of the systemic alternative of the planned economy), in this case, it is rather 
1 the need for a source of legitimation given a policy agenda which is increasingly oriented towards

2 supranational governance, technocratic in spirit, and market oriented (Bogliacino et al 2015;

3 Codagnone et al. 2018; Gueron, 2017).

4 Whereas no plausible argument can be raised against the use of evidence to improve decision-

5 making, mounting critiques have been raised against the use of experts as arguments in favor of

6 certain policy options. While evidence is assumed to be transparent, the use of experts can reduce

7 accountability because it obliterates the arguments of the opposing parties using ex authoritate

8 statements (Dehue, 2002). The shift from evidence to experts in EBP is somewhat natural for a

9 number of reasons. First, the policy cycle and the evidence cycle are not synchronic, i.e.

10 authorities cannot wait for the evidence to be conclusive before making a decision. Second,

11 science and policy entail different languages, and simplification and rhetoric may pave the way

12 to normative or cognitive selection in the presentation of evidence (Strassheim and Kettunen,

13 2014). One proposed alternative is the deliberative approach, which refers to citizen mobilization

14 and civil society's potential provision of policy-relevant information (Carrozza 2014). This

15 alternative has been harshly criticized, on the ground that the modern reduction of entry costs

16 in the public debate due to social media has fueled the post truth politics, via weakening of the

17 binding nature of norms of self-regulation internalized by traditional media (Lazear et al. 2018),

18 and increasing polarization of the public (with mixed evidence, Zhuravskaya et al. 2020).

19 This semantic shift from evidence to expert in EBP (or from evidence to civic society in the

20 deliberative approach) highlights one key aspect of how to reach legitimacy. Communication is

21 as important as the content itself. This is not surprising from a psychological point of view

22 because it boils down to the very definition of framing. A framing effect occurs when a

23 decisionmaker violates consistency of preferences: while facing the same choice set, she picks

24 up a different option only because the choice architecture is different. From the original work 
1 by Tversky \& Kahneman (1981), it has been applied extensively in politics (Benford \& Snow,

2 2000; Klandermans, 1997; Snow \& Benford, 1988; Snow et al., 1986) and in the last two decades

3 increasingly also into the study of policymaking communication strategies (Béland et al. 2016;

4 Carstensen \& Schmidt 2016; Seabrooke \& Wigan 2016; Mügge 2016; Jones et al., 2014; Maor,

5 2014; Maor, 2016). Given a policy contested issue, opponents can adopt framing strategies to

6 shape the behavioral response and to privilege a specific interpretation of facts (Kuypers, 2010),

7 usually, according to Entman (1993: 51-52), by selecting some aspects of a given situation and

8 make them more salient in a text, with the goal of promoting 'a particular problem definition, causal

9 interpretation, moral evaluation, and/ or treatment recommendation for the item described' (1993, p. 52).

10 The use of experts as a communication strategy poses at least two questions. From a

11 normative point of view, is it desirable to delegate to experts the justification of a policy? From

12 a positive point of view, is expert endorsement more effective than alternative communication

13 strategies?

14 In this paper we focus on the latter questions. For the normative argument, models of 15 strategic interactions where agents are rational (using variations of Crawford and Sobel, 1982)

16 show that democracy can be captured by experts, when these have their own agenda which is

17 not aligned with the best policy option according to the median voter. The main claim of this

18 literature is that expert captured democracy can still be welfare improving, but when

19 counterbalanced by a strong populist opposition (Chakraborty et al 2020). Bogliacino et al (2019)

20 show that a policy should be placed in a three dimensional space where interest, value and

21 uncertainty are the coordinates, and that neither citizen mobilization nor expert delegation is

22 necessarily the first best, because they are more or less prone to bias, depending on the region

23 of the policy space. For example, high rents to be shared make delegation to experts very risky 
1 (as in the famous sugar case, Kearns et al 2016), while value conflicts make evidence produced

2 via citizen mobilization particularly biased (Pielke, 2007).

3 Coming to the positive analysis, we think that the research question should be further 4 expanded. First, an alternative treatment should be defined: experts' justification can be compared 5 with infinite other arguments. Following the critiques on evidence-based policies coming from 6 deliberative and post normal science (Funtowicz and Ravetz, 2018), one alternative is obviously 7 a communication strategy based on deliberative support by citizen mobilization. Nevertheless, 8 as stated in Bogliacino et al. (2019), a further alternative is negotiated conflict. This is an 9 alternative to expert endorsement or civic society mobilization, in that it does recognize the 10 production of partisan evidence as biased, but claim that the public arena, where these conflicting 11 views are opposed, is capable of filtering out weak evidence which does not sustain public 12 scrutiny, as it happens in the adversarial system (Posner, 1999). As argued by Nielsen and 13 Pedersen (1988), this corresponds also to the Scandinavian model of negotiation by independent 14 bodies, interacting without the use of legal sanctions, whose ultimate outcome is the shaping of 15 collective preference. This negotiated conflict communication recognizes ex ante the bias in 16 alternative positions and the choice of the policy as the mediation between them.

17 Second, we need to compare the efficacy of experts versus the counterfactual communication 18 strategies not only in the baseline scenario, but under different framings. We follow Bogliacino 19 et al (2019) in positing that according to where we stand in the policy space, the relative value of 20 the evidence produced from experts may change, altering the relative strength of an argument if 21 beliefs are correctly updated. As mentioned before, the policy space is defined by three axes: 22 uncertainty, values, and interests. Epistemic uncertainty refers to the robustness of our knowledge 23 in terms of internal and external validity. Values refer to whether there is a shared commitment 24 to a specific goal or rather conflicting commitments stemming from different preferences. 
1 Interests, or to be more precise, rents, refers to the classical Olsonian distinction between

2 specific (alternatively called concentrated) and diffuse interests (Olson, 1971 [1965]). Rent

3 seeking may distort the production of evidence in support of a policy and may raise suspicions

4 over a supporting party. When we prime citizens with respect to uncertainty, values, and

5 interests, do they react differently to communication strategies which are expert based,

6 deliberative or negotiated? Additionally, what happens when sources of tension along these

7 dimensions materialize, i.e. when uncertainty is high, there is value conflict, and there are

8 significant interests at play?

9 In the contingency of Covid19, the way in which legitimacy is carved out is important for a

10 number of reasons. First, the declaratory of emergency in most of the countries paved the way

11 to an imbalance between the parliament and the government, in favor of the latter, with a

12 widespread use of urgency motivated decrees which obviously did not follow the standard

13 legislative process. As a result, these decisions are less legitimate from a procedural point of view,

14 and the core source of legitimacy shifts to the substantive. Second, facing a pandemic requires an

15 active role of citizens in compliance with the norms introduced, which goes beyond simple

16 acceptance of the choices made by the government: citizens need to be convinced to change

17 their behavior. Third, this contingency corresponds also to a major uncertainty shock: this means

18 that governments are expected to make many relevant decisions in a short window of time and

19 potentially facing future outbursts. This has something in common with the beginning of a

20 mandate where analysts usually stress that the extent to which legitimacy is established explains

21 newcomers' degree of success (Tyler, 2006).

\section{Data and Analysis}


2 We submit a link to a random sample of participants to an online panel in three countries:

3 Italy, Spain, and the UK. The study is preregistered on OSF (Bogliacino et al. 2020b). Ethical

4 approval was obtained from the Institutional Review Board of the Universitat Oberta de

5 Catalunya. All respondents provided informed consent.

6 This article is based on data from wave three, which were collected between the $10^{\text {th }}$ of May

7 and the $20^{\text {th }}$ of May. Upon accepting to proceed to the questionnaire, participants were asked to

8 read a text. There were six such texts, of around 90 words, classified into three groups: related

9 with the available data on the mortality of the virus (uncertainty framing), on the use of technology

10 as a tool to control the spread of the pandemic (values framing), or on the potential economic

11 costs of the mitigation strategies (interests framing). Within each framing, we have two versions

12 of the text, which usually differ in one or two sentences, a version which is uncontested

13 (uncertainty is low, technology is good, and we should not focus on the economy right now),

14 and another version where we stress the presence of conflicting stances (epistemic uncertainty

15 is high, control via technology is potentially risky, economic costs of mitigation are high). It is

16 important to state that we never deceive participants, we simply present different positions using

17 general references from the press.

18 After reading the text, participants are asked to rate three policies, they first read the text of 19 the policy, then the text of a supporting argument, and are asked to rate on a 1 to 7 Likert scale,

20 their approval of the policy (Q1: level of agreement with "I would support this policy if proposed

21 to be implemented in my country"), their approval for the argument in support (Q2: "I think

22 that this is a solid argument to convince me to support this policy"), and their support for the

23 argument as part of a communication strategy by their government to justify the adoption of the 
1 policy (Q3: "I would like this message to be part of the communication strategy of the

2 government"). Policies are evaluated in random order. The three policies are: a slightly softened

3 version of the lockdown, a trace and isolate policy (based on an app), and a test and release

4 policy (based on serologic tests). We label the supporting arguments as expert based, deliberative,

5 or negotiated conflict. Expert based are ex authoritate arguments suggesting that the policy should

6 be adopted because it has been recommended by experts. Deliberative suggests that policies

7 have been recommended by consultation with the civil society. Negotiated conflict explicitly

8 recognizes conflicting views and suggests that the policy is a mediation between them. Texts of

9 the priming, of the policies and of the questions are in Annex. In Figure 1 below, we explain

10 graphically the experimental flow. 
Merge each policy with an argument. Random order

(Random draw without replacement)

Likert scale (1-7) for each policy
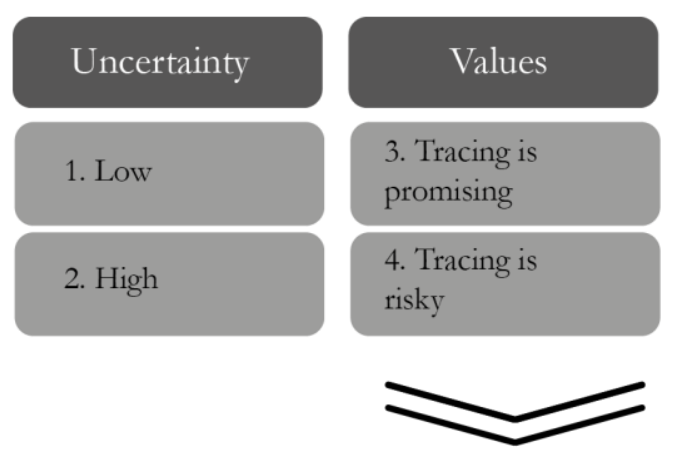

Policy Q. Softened

lockdown

Policy T. Trace and

isolate

Policy D. Test and

release

5. Do not worry

for the economy

6. Economic

costs are high

\section{Argument 1. Expert-based}

Argument 2. Deliberative

Argument 3. Negotiated conflict

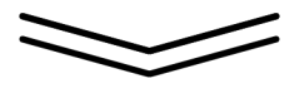

\section{Q1. Approval of the policy}

\section{Q2. Approval of the argument in support}

Q3. Support of the argument as a part of a communication strategy by the government

3 Once we consider the match between the policies and the types of argument, we have six

4 possible conditions. This is the first factor. The second factor is the priming (six conditions). In

5 total we have 36 experimental conditions, randomly assigned. This is pictured in Figure 2 below,

6 where we also report number of observations per cell. 


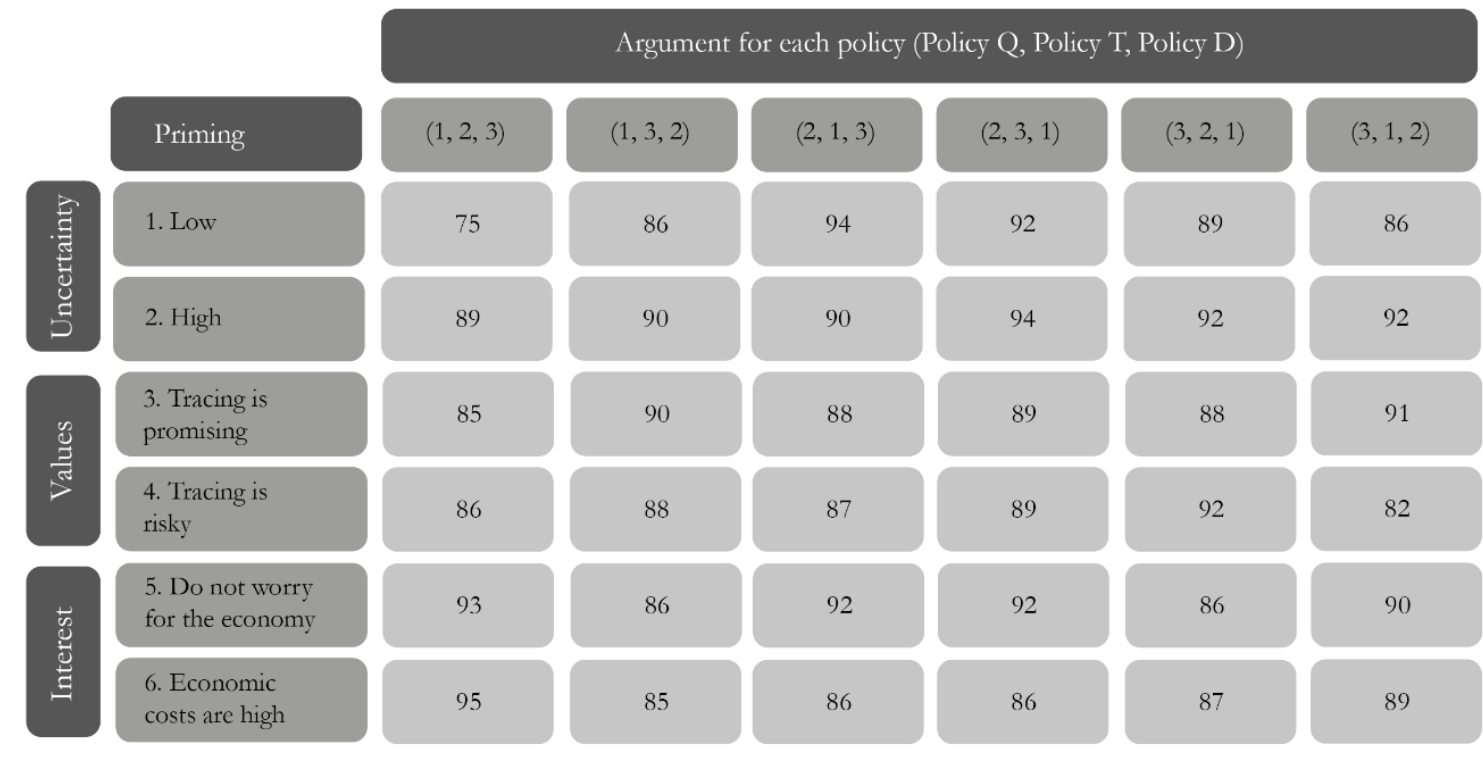

We chose social isolation as baseline policy, allowing people to leave their houses for strictly urgent matters only. This is still considered to be the default strategy in all countries in presence of new outbursts (Chudik et al, 2020). As alternatives, we consider tracing via an app, which has

9 been proposed as a smart solution and has proved to be effective in China and especially in

10 Korea (Bagchi et al, 2020; Silver \& Cyranoski, 2020), and the proposal of massive testing and 11 release, which was first proposed by Paul Romer with regards to PQR testing, i.e. the tampon 12 that detects if one is currently infected (Romer, 2020) and then suggested for antigen testing 13 which is able to detect if a person had ever contracted the virus (Taipale et al, 2020).

14 We first analyze and explain the priming strategy. The priming is a short text of around 90 15 words, usually composed of two sentences. To avoid loss of control, we do not cite directly 
names or sources, but we never deceive participants. The first two texts are related with epistemic

2 uncertainty. In the first, we state as evidence the numbers that were proposed when pushing for

3 full closure. These come from modelling exercises which have later been criticized for both code

4 and assumptions (Barton et al, 2020; Shen et al, 2020). We consider this our control condition

5 because this is the prevailing framing in the media. The high uncertainty priming is based on the

6 results of a few studies that challenged the prevailing pro-lockdown narrative, according to which

7 prevalence is much higher than what suggested by current numbers (Ioannidis, 2020; Melnick \&

8 Ioannidis, 2020).

9 When we consider the debate over "values", the current debate has been polarized over the 10 conflict between preserving health system and protecting freedom. We use technology and 11 tracking to prime over conflict of values. Both texts refer to the use of technology, but one (value 12 consensus) stresses how promising and effective can be, while the other stresses how it can lead 13 to government control.

14 Finally, to prime over interests, recalling that during the worst of the emergency in the three 15 countries, there was a tendency to frame the debate in terms of health versus the economy, 16 suggesting that those promoting a reopening were simply pushed by interests groups that were 17 afraid of losing income, we use two texts, one maintaining a position that health should be the 18 only focus, while the second is referring to the potential aggregate negative shock.

19 Finally, we illustrate the supporting arguments. These texts are 60-90 words long, and 20 although they are tailored over the specific policy, they are variations of the same model. The 21 baseline argument is simply an expert endorsement. It usually reads "Expert were consulted and 22 state that the policy $[\ldots]$. According to the experts, $[\ldots]$ ”. The second argument (deliberative) 23 refers to a consultation of the civic society, which has then endorsed the policy. It starts with 
1 the sentence "The government has consulted with the citizens on this policy and participants

2 argue that $[. .$.$] ". Finally, the negotiated conflict is an argument that is based on the opposition$

3 between the experts and another subset of the public opinion ("The government has listened to

4 different arguments [...]"), stressing biases of both. Given the three types of supporting

5 arguments per each policy and three policies, we match each policy with a different argument

6 and ask participants to rate them, in random order.

\subsection{Analysis plan}

9 We perform two types of analysis: non-parametric tests and regression analysis. The first class

10 of tests is aimed at assessing differences in approval of policies and arguments.

11 We then compute regression analysis to estimate the treatment effects. To interpret the 12 coefficients, we use the standard switching regression formulation. For each policy, we define $Y$

13 as the outcome variable, $Y_{i}^{j, k, z}$ is the rating of the plausibility of the argument and of the 14 suitability for the communication strategy by subject $i$, to argument $j$ (expert, exp, del, neg), under 15 priming $k(v, i, u$, where $u$ is uncertainty) and condition $z$ ( $h$, high, or low $l)$. We will group together 16 values, interests, and uncertainty under condition low, as our control condition (c).

17 Our hypotheses are based on the results of Bogliacino et al. (2019), where it is argued that in 18 the consensual domain (value consensus, low epistemic uncertainty, diffused interests), experts' 19 knowledge is more reliable and thus should be ranked higher. We expect:

$$
E\left[\left(Y_{i}^{d e l, c}-Y_{i}^{e x p, c}\right)\right]<0
$$

$$
E\left[\left(Y_{i}^{n e g, c}-Y_{i}^{e x p, c}\right)\right]<0
$$


2 expect citizen to rely more on consultative recommendation. Finally, in presence of conflict of

3 values or interests, we expect honest recognition of existing biases and mediation as more

4 legitimate supporting argument. In other words, we formulate the following hypotheses:

$5 \quad E\left[\left(Y_{i}^{\text {neg,v,h }}-Y_{i}^{\text {exp,v,h }}\right)\right]>0$

$6 \quad E\left[\left(Y_{i}^{\text {neg,i,h }}-Y_{i}^{\text {exp }, i, h}\right)\right]>0$

$7 \quad E\left[\left(Y_{i}^{d e l, u, h}-Y_{i}^{e x p, u, h}\right)\right]>0$

8 We run a difference-in-difference models using $D_{i}^{n e g}, D_{i}^{\text {del }}$, the two dummies for the

9 negotiated and deliberative arguments, $D_{i}^{v, h}, D_{i}^{u, h}, D_{i}^{i, h}$, the three dummies for the priming of

10 value conflict, high uncertainty, and conflicts of interests, and the six interactions. We run OLS

11 with robust standard errors. Estimates of [1] and [2] are the coefficients of the dummies $D_{i}^{\text {neg }}$,

$12 D_{i}^{\text {del }}$. To estimate [3]-[5], we perform standard t-test using linear combination of the coefficients.

13 These hypotheses were preregistered (on April 13 ${ }^{\text {th }}$, Bogliacino et al., 2020a).

\section{Results}

16 We collect responses from 3191 participants, 1021 in Spain, 1138 in the UK and 1032 in Italy;

$1752.52 \%$ are female, average age is 47.66 (13.08 SD), $42.59 \%$ has at most high school, $65.37 \%$ is

18 married or living with the partner, median household size is 3. The socio-economic profile is the

19 following: by income, in Spain, 54.84\% declares an income at or below the median in the country,

20 in the UK it is $48.59 \%$, in Italy, $56.1 \% ; 52.27 \%$ lives in urban area; $61.42 \%$ is employed; $71.92 \%$ 
1 owns or is currently paying the house where the household lives; the median residential space is

2100 square meters.

3 Participants were asked to rate their approval of three policies: social isolation (baseline), 4 tracing via app, and serologic testing. In Figure 3 below, we report the average approval. We 5 break down approval by country. In Spain, differences are not statistically significant (for the 6 three comparisons, $\mathrm{z}=1.52 ; \mathrm{z}=0.28 ; \mathrm{z}=-1.04$, in all cases $\mathrm{p}>0.10)$. The $\mathrm{UK}$ government was 7 allegedly pursuing a herd behavior strategy that was harshly criticized, before reverting to 8 lockdown. It can be seen that the baseline policy is still preferred to alternative policies that entails 9 freeing the economy (Wilcoxon signed rank test, for policy one versus two, $\mathrm{z}=6.84, \mathrm{p}<0.0001$; 10 for policy one versus three, $\mathrm{z}=9.84, \mathrm{p}<0.0001)$; however, tracing is preferred to testing, although 11 the significant difference is practically very thin $(\mathrm{z}=3.80, \mathrm{p}=0.0001)$. In Italy, tracing has a low 12 rating, probably reflecting the traditional suspicion for governmental management of personal 13 data. In fact, it received a significantly lower approval than social isolation $(z=2.62, p<0.01)$ and 14 testing $(\mathrm{z}=-3.04 ; \mathrm{p}<0.01)$, while there is no difference between social isolation and testing $(\mathrm{z}=$ $150.64, \mathrm{p}=0.51)$. Overall, there are significant differences of approval between the social isolation 16 policy and tracing (Wilcoxon Signed rank, $\mathrm{z}=6.42, \mathrm{p}<0.0001$ ), and between the social isolation 17 and testing $(\mathrm{z}=5.77, \mathrm{p}<0.0001)$, but not between tracing and testing $(\mathrm{z}=0.015, \mathrm{p}=0.98)$.

18 In Table 1 below, columns (1)-(3), we report the average approval for the arguments, broken 19 down by policy. In case of social isolation there are significant differences in terms of approval 20 of supporting argument. In particular, expert endorsement is rated as more convincing (Kruskal 21 Wallis, $\left.\chi^{2}(2)=18.45, \mathrm{p}<0.001\right)$. The same applies for testing $\left(\chi^{2}(2)=40.10, \mathrm{p}<0.0001\right)$. This is not 22 the case for tracing, where there are not systematic differences across arguments $\left(\chi^{2}(2)=2.92\right.$, $23 \mathrm{p}=0.23)$. 
2 strategy, again broken down by policy. The pattern mimics the previous question. In particular,

3 expert endorsement is preferred in case of social isolation (Kruskal Wallis, $\chi^{2}(2)=9.46, \mathrm{p}<0.01$ )

4 and testing $\left(\chi^{2}(2)=40.23, \mathrm{p}<0.0001\right)$, but not for tracing $\left(\chi^{2}(2)=1.94, \mathrm{p}=0.37\right)$. Notice that in all

5 cases, differences are relatively small, but the large sample allows to distinguish statistically the

6 ratings.

7

8

Figure 3 Average approval of policies, broken down by country

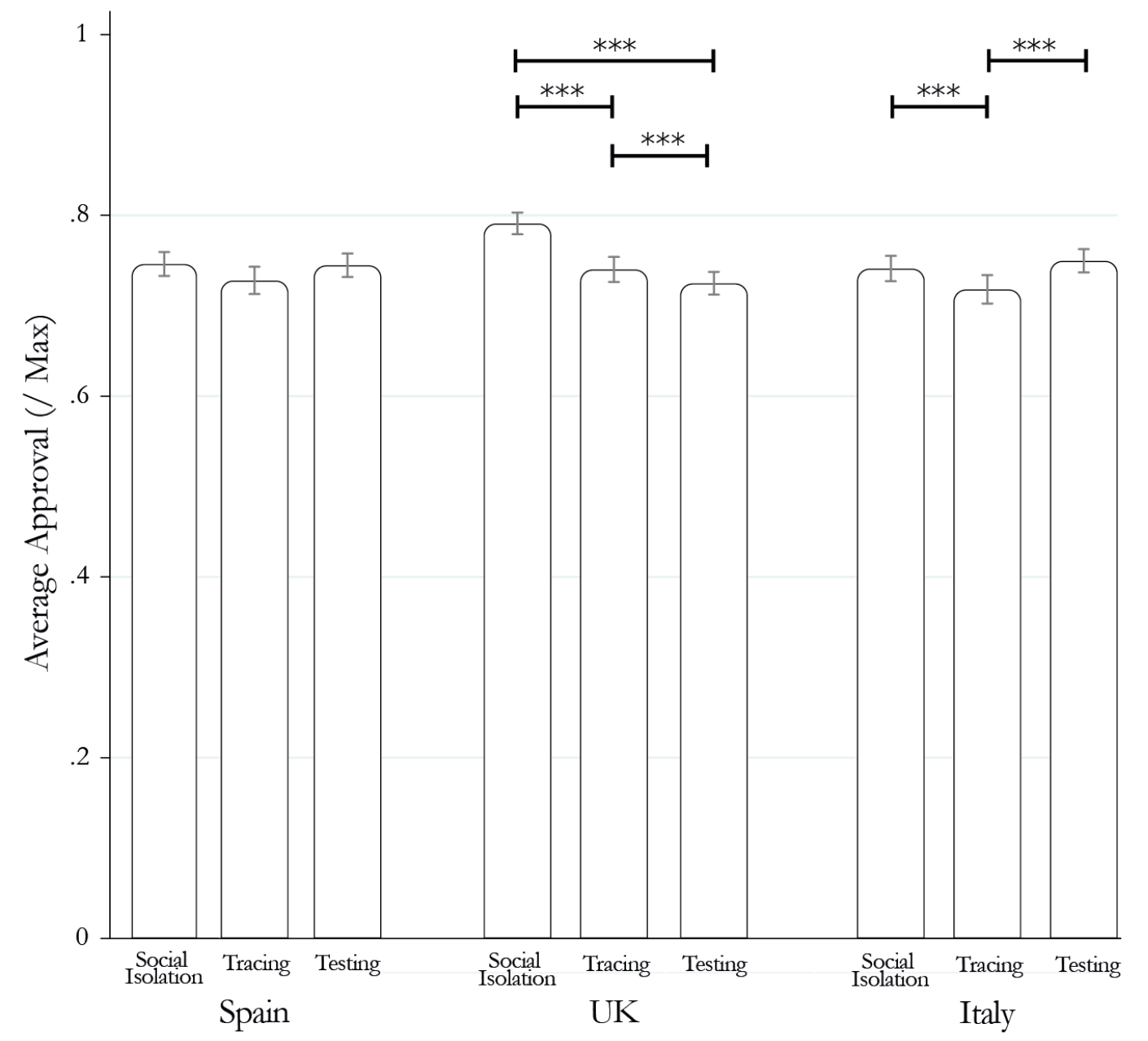

Note: Error bars indicate confidence interval at $95 \%$. We also report the significant differences between groups 
Table 1 Average approval of arguments and of communication strategy, broken down by policy

\begin{tabular}{|l|l|l|l|l|l|l|}
\hline & \multicolumn{3}{|l|}{ Approval of supporting argument } & \multicolumn{2}{l|}{ Approval of communication strategy } \\
\hline & $\begin{array}{l}\text { Expert } \\
(1)\end{array}$ & $\begin{array}{l}\text { Deliberative } \\
(2)\end{array}$ & $\begin{array}{l}\text { Negotiated } \\
(3)\end{array}$ & $\begin{array}{l}\text { Expert } \\
(4)\end{array}$ & $\begin{array}{l}\text { Deliberative } \\
(5)\end{array}$ & $\begin{array}{l}\text { Negotiated } \\
(6)\end{array}$ \\
\hline $\begin{array}{l}\text { Social } \\
\text { Isolation }\end{array}$ & 0.76 & 0.75 & 0.73 & 0.75 & 0.73 & 0.72 \\
& $(0.21)$ & $(0.21)$ & $(0.20)$ & $(0.22)$ & $(0.22)$ & $(0.21)$ \\
\hline Tracing & 0.72 & 0.71 & 0.70 & 0.71 & 0.70 & 0.70 \\
& $(0.23)$ & $(0.24)$ & $(0.24)$ & $(0.24)$ & $(0.24)$ & $(0.24)$ \\
\hline Testing & 0.75 & 0.69 & 0.70 & 0.74 & 0.69 & 0.70 \\
& $(0.21)$ & $(0.22)$ & $(0.21)$ & $(0.21)$ & $(0.22)$ & $(0.22)$ \\
\hline Overall & 0.74 & 0.71 & 0.71 & 0.73 & 0.71 & 0.71 \\
& $(0.22)$ & $(0.22)$ & $(0.22)$ & $(0.22)$ & $(0.23)$ & $(0.22)$ \\
\hline
\end{tabular}


In Figure 4 and 5 below, we report the average approval of respectively the arguments and

2 the communication strategies, pooled across policies but broken down by experimental

3 condition to directly test hour hypotheses. We also report the result of a MWW test.
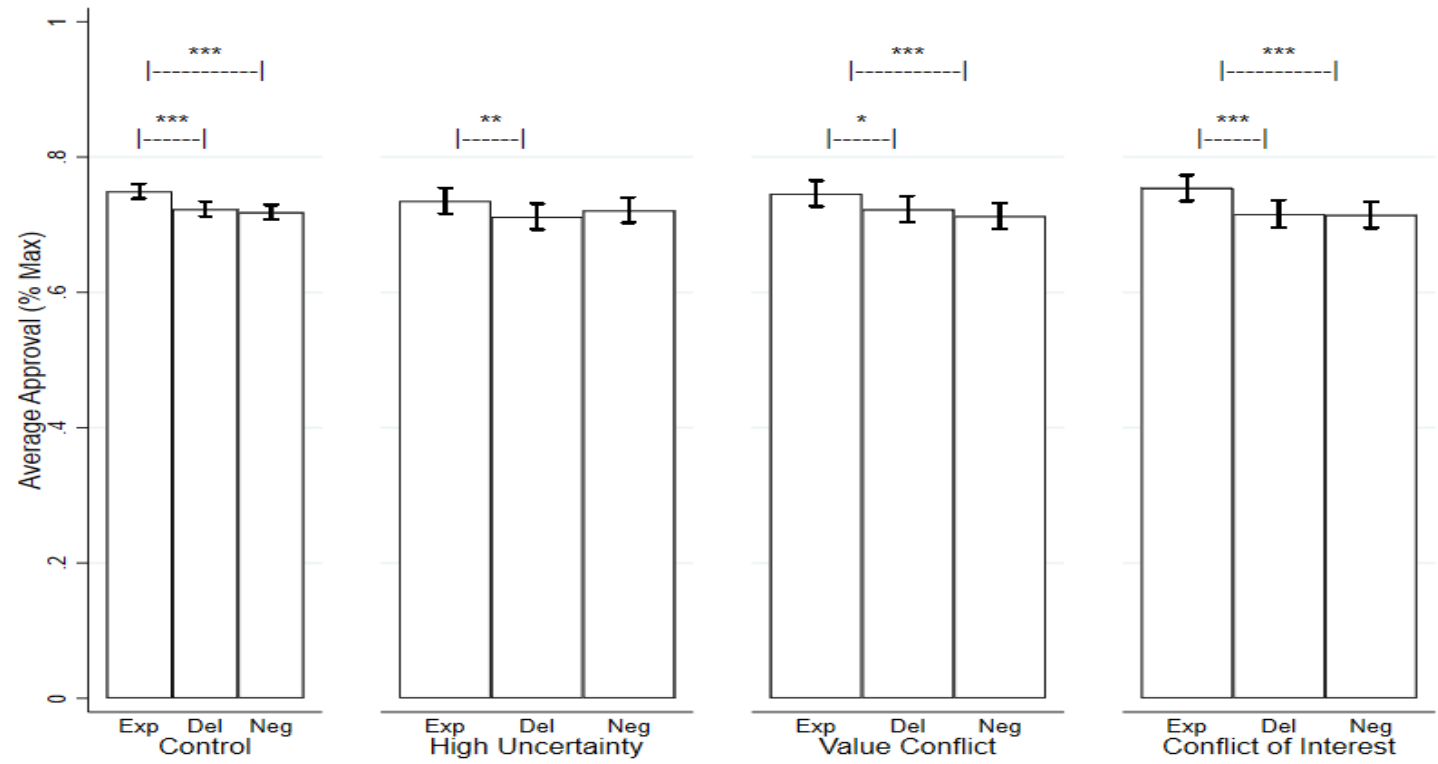

6 Note: Error bars indicate confidence interval at 95\%. We also report the significant differences between groups 7 from Wilcoxon signed rank test, ${ }^{*} \mathrm{p}<0.1,{ }^{* *} \mathrm{p}<0.05,{ }^{* * *} \mathrm{p}<0.01$. 

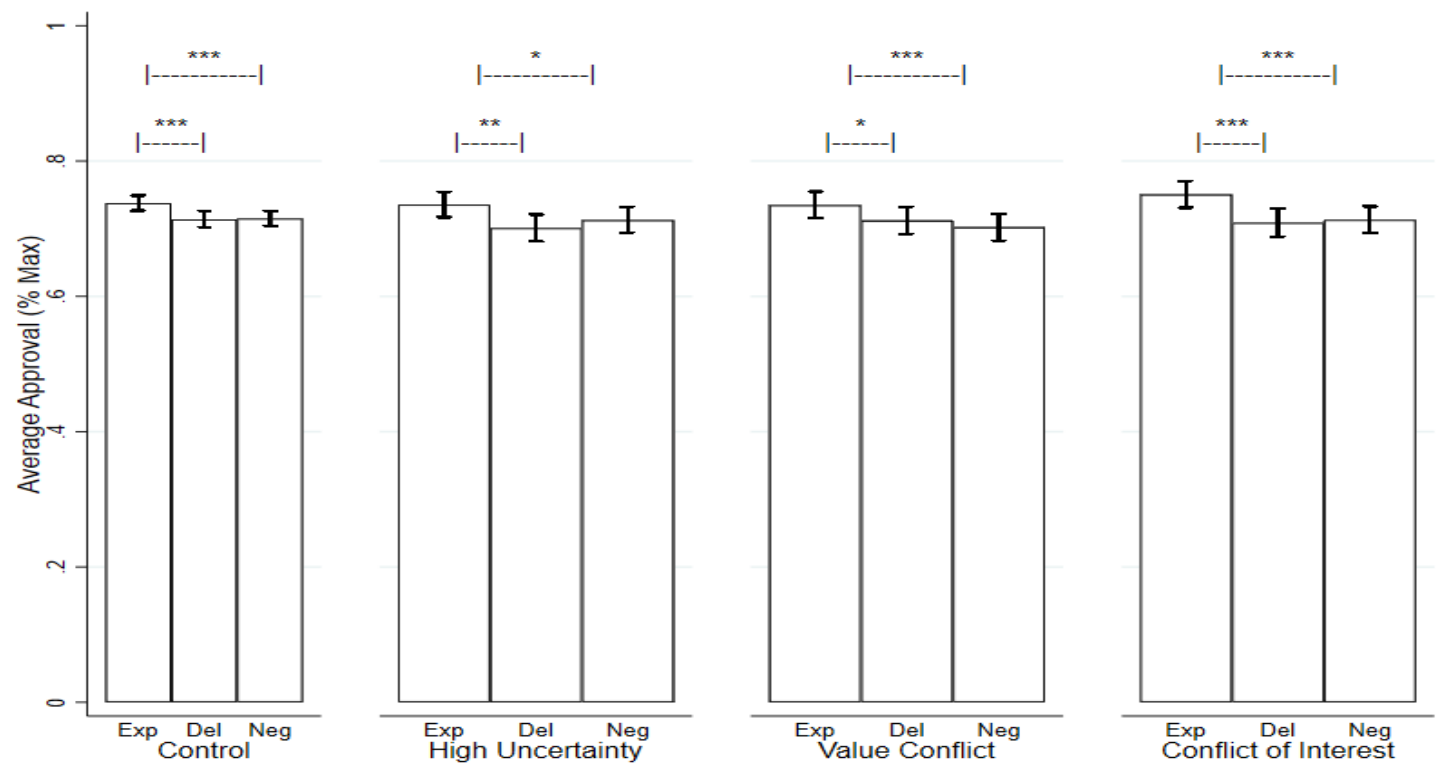

3 Note: Error bars indicate confidence interval at 95\%. We also report the significant differences between groups 4 from Wilcoxon signed rank test, ${ }^{*} \mathrm{p}<0.1,{ }^{* *} \mathrm{p}<0.05,{ }^{* * *} \mathrm{p}<0.01$. 
Figure 4 and 5 show that expert endorsement is clearly preferred to alternative arguments.

3 The first panel on the left in Figure 4 fails to reject our hypothesis, as expert is valued more than

4 other arguments (respectively, $\mathrm{z}=3.43, \mathrm{p}<.001$ and $\mathrm{z}=4.50, \mathrm{p}<.001$ ). However, data do not

5 support our three additional hypotheses. In case of high uncertainty, expert endorsement is still

6 valued the highest and statistically different at least from consultation ( $z=2.07, p=0.03)$; whereas

7 for value conflict and conflict of interests, expert endorsement is on aggregate preferred to the

8 other two arguments (value: $z=1.04, p=.05 ; z=2.76, p<.01$; interests, $z=2.65, p<.01 ; z=3.37$,

$9 \mathrm{p}<.01)$. The results in Figure 5 are essentially the same: in the control condition, expert

10 endorsement is valued more $(z=3.03, p<.01$ and $z=3.14, p<.01)$, the same happens for high

11 uncertainty - this being the main difference with respect to the previous outcome variable -

$12(\mathrm{z}=2.35, \mathrm{p}=0.01$ and $\mathrm{z}=1.92, \mathrm{p}=.05)$, for value conflict $(\mathrm{z}=1.82, \mathrm{p}=.06$ and $\mathrm{z}=2.65, \mathrm{p}<.01)$, and

13 for conflict of interests $(\mathrm{z}=3.03, \mathrm{p}<.01$ and $\mathrm{z}=3.11, \mathrm{p}<.01)$.

14 Finally, in Table 2 below, we report the regression analysis, where we test the main

15 hypotheses. We were expecting a higher ranking of expert endorsement with respect to other

16 arguments in the control condition. Data are consistent with this hypothesis. For social isolation,

17 under consensus domain, the expert endorsement is preferred to deliberative $(t=-2.29, \mathrm{p}=0.02)$

18 and negotiated $(\mathrm{t}=-2.89, \mathrm{p}<0.01)$. For tracing, deliberative and negotiated are not valued

19 differently from experts under consensus domain ( $\mathrm{t}=0.86, \mathrm{p}=0.38 ; \mathrm{t}=-1.37, \mathrm{p}=0.17$ respectively).

20 For testing, results are in line with those of social isolation (column 3), namely the expert

21 endorsement is preferred to deliberative $(t=-5.38, p<0.01)$ and negotiated $(t=-4.47, p<0.01)$ in

22 the control condition. Results are qualitatively the same when we directly ask to rate the

23 argument in support of a communication strategy. In the case of social isolation, deliberative

24 and negotiated are rated less than expert argument under consensus domain, but difference is 
statistically significant only in the latter case $(t=-1.40, p=0.16$ and $t=-2.16, p=0.03)$. In the case

2 of tracing (column 5), deliberative and negotiated are rated respectively more and less than

3 expert, but the difference is not statistically significant $(\mathrm{t}=0.48, \mathrm{p}=0.62 ; \mathrm{t}=-0.27,0=0.78)$. Finally,

4 for testing (column 6$)$, the expert endorsement is preferred to deliberative $(t=-5.18, p<0.01)$ and

5 negotiated $(\mathrm{t}=-4.43, \mathrm{p}<0.01)$.

6 The evidence is either non conclusive or contrary to expectations with regards to the other

7 three hypotheses. The relevant coefficients are reported in the three bottom lines of Table 2. We

8 were expecting a higher ranking of deliberative with respect to expert endorsement under high

9 uncertainty priming. Starting from the rating of the argument, we cannot reject lack of difference

10 in case of social isolation $(t=0.17, \mathrm{p}=0.86)$ and testing $(\mathrm{t}=-0.77, \mathrm{p}=0.44)$, whereas data go

11 opposite to our hypothesis in case of tracing $(\mathrm{t}=-2.15, \mathrm{p}=0.03)$. When asked to rate the

12 communication strategy, participants confirm the main results. In case of social isolation, we

13 cannot reject lack of difference $(\mathrm{t}=0.58, \mathrm{p}=0.56)$, nor in the case of testing $(\mathrm{t}=-1.24, \mathrm{p}=0.21)$.

14 For the tracing policy, data show that expert endorsement is ranked higher $(\mathrm{t}=-3.47, \mathrm{p}<0.01)$.

15 We were also expecting negotiation to be a better ranked argument under value or interest

16 conflicts. Starting from the overall rating of the argument, in case of social isolation, support is

17 higher for expert endorsement under value conflict $(t=-1.65, p=0.09)$ and conflict of interests

$18(\mathrm{t}=-1.72, \mathrm{p}=0.08)$. In case of tracing, data go contrary to our hypotheses for value conflict $(\mathrm{t}=$ -

$191.72, p=0.08)$ and show no difference in case of conflict of interests $(t=0.35, p=0.72)$. In case of

20 testing, data again go against our hypotheses for conflict of interests $(t=-2.41, p=0.01)$ and show

21 no difference in case of value conflict $(\mathrm{t}=-0.90, \mathrm{p}=0.36)$. Moving to the evaluation of the

22 communication strategy, in case of social isolation, data are inconsistent with our hypotheses in

23 case of value conflict $(\mathrm{t}=-1.67, \mathrm{p}=0.09)$, whereas there is lack of difference in case of conflict of 
1 interests $(\mathrm{t}=-0.77, \mathrm{p}=0.44)$. In the case of tracing, data suggest that expert endorsement is 2 preferred in the case of value conflict $(t=-1.63, p=0.10)$ and show no difference in case of 3 conflict of interests $(t=0.50, \mathrm{p}=0.61)$. Finally, for the case of testing, in both cases there is a 4 higher ranking for expert endorsement, although this is not statistically significant for the case 5 of value conflict $(t=-0.80, p=0.42)$, while it is for the conflict of interest $(t=-2.08, p=0.03)$.

6 In Table 2, we also report the estimation of the interaction terms. For any argument of 7 interests (deliberative or negotiated) and any priming of contested domain (high uncertainty, 8 value conflict, conflict of interests), these figures report the impact of the priming on the 9 evaluation of the argument in question with respect to the impact of the priming on the 10 evaluation of expert endorsement. The evidence is largely inconclusive. 


\begin{tabular}{|c|c|c|c|c|c|c|}
\hline & $\begin{array}{c}(1) \\
\text { Social } \\
\text { Isolation } \\
\end{array}$ & $\begin{array}{c}(2) \\
\text { Tracing }\end{array}$ & $\begin{array}{c}\text { (3) } \\
\text { Testing }\end{array}$ & $\begin{array}{c}(4) \\
\text { Social } \\
\text { Isolation } \\
\end{array}$ & $\begin{array}{c}\text { (5) } \\
\text { Tracing }\end{array}$ & $\begin{array}{c}(6) \\
\text { Testing }\end{array}$ \\
\hline & \multicolumn{3}{|c|}{ Approval of the argument } & \multicolumn{3}{|c|}{$\begin{array}{c}\text { Approval of the communication } \\
\text { strategy }\end{array}$} \\
\hline \multirow[t]{2}{*}{$E\left(Y_{i}^{d e l, c}-Y_{i}^{e x p, c}\right)$} & $-0.03 * *$ & 0.01 & $-0.07 * * *$ & -0.02 & 0.01 & $-0.07 * * *$ \\
\hline & $(0.01)$ & $(0.01)$ & $(0.01)$ & $(0.01)$ & $(0.01)$ & $(0.01)$ \\
\hline \multirow{2}{*}{$E\left(Y_{i}^{n e g, c}-Y_{i}^{e x p, c}\right)$} & $-0.04 * * *$ & -0.02 & $-0.05^{* * *}$ & $-0.03 * *$ & -0.00 & $-0.05^{* * *}$ \\
\hline & $(0.01)$ & $(0.01)$ & $(0.01)$ & $(0.01)$ & $(0.01)$ & $(0.01)$ \\
\hline \multirow{2}{*}{$E\left(Y_{i}^{\text {exp }, u, h}-Y_{i}^{\text {exp,c }}\right)$} & -0.03 & 0.01 & $-0.03^{*}$ & -0.03 & $0.04 *$ & -0.03 \\
\hline & $(0.02)$ & $(0.02)$ & $(0.02)$ & $(0.02)$ & $(0.02)$ & $(0.02)$ \\
\hline \multirow{2}{*}{$E\left(Y_{i}^{\text {exp }, v, h}-Y_{i}^{\text {exp,c }}\right)$} & -0.00 & 0.02 & $-0.03^{*}$ & 0.00 & 0.02 & $-0.04 * *$ \\
\hline & $(0.02)$ & $(0.02)$ & $(0.02)$ & $(0.02)$ & $(0.02)$ & $(0.02)$ \\
\hline \multirow{2}{*}{$E\left(Y_{i}^{e x p, i, h}-Y_{i}^{e x p, c}\right)$} & -0.00 & -0.01 & 0.00 & -0.00 & 0.00 & 0.01 \\
\hline & $(0.02)$ & $(0.02)$ & $(0.01)$ & $(0.02)$ & $(0.02)$ & $(0.01)$ \\
\hline \multirow{2}{*}{$\begin{array}{l}E\left[\left(Y_{i}^{\text {del,u,h }}-Y_{i}^{\text {del,c }}\right)\right. \\
\left.-\left(Y_{i}^{\text {exp }, u, h}-Y_{i}^{\text {exp }, c}\right)\right]\end{array}$} & 0.03 & $-0.07 * *$ & $0.05^{* *}$ & 0.03 & $-0.10^{* * *}$ & $0.04 *$ \\
\hline & $(0.03)$ & $(0.03)$ & $(0.03)$ & $(0.03)$ & $(0.03)$ & $(0.03)$ \\
\hline \multirow{2}{*}{$\begin{array}{l}E\left[\left(Y_{i}^{d e l, v, h}-Y_{i}^{d e l, c}\right)\right. \\
\left.-\left(Y_{i}^{\text {exp }, v, h}-Y_{i}^{e x p, c}\right)\right]\end{array}$} & -0.02 & -0.01 & $0.05^{*}$ & -0.04 & -0.00 & $0.05^{*}$ \\
\hline & $(0.03)$ & $(0.03)$ & $(0.03)$ & $(0.03)$ & $(0.03)$ & $(0.03)$ \\
\hline \multirow{2}{*}{$\begin{array}{l}E\left[\left(Y_{i}^{d e l, i, h}-Y_{i}^{d e l, c}\right)\right. \\
\left.-\left(Y_{i}^{e x p, i, h}-Y_{i}^{e x p, c}\right)\right]\end{array}$} & 0.02 & -0.03 & -0.00 & 0.01 & -0.02 & -0.00 \\
\hline & $(0.03)$ & $(0.03)$ & $(0.02)$ & $(0.03)$ & $(0.03)$ & $(0.02)$ \\
\hline \multirow{2}{*}{$\begin{array}{l}E\left[\left(Y_{i}^{n e g, u, h}-Y_{i}^{n e g, c}\right)\right. \\
\left.-\left(Y_{i}^{\text {exp } u, h}-Y_{i}^{\text {exp,c }}\right)\right]\end{array}$} & 0.04 & 0.01 & 0.02 & 0.03 & -0.04 & 0.02 \\
\hline & $(0.03)$ & $(0.03)$ & $(0.03)$ & $(0.03)$ & $(0.03)$ & $(0.03)$ \\
\hline \multirow{2}{*}{$\begin{array}{l}E\left[\left(Y_{i}^{\text {neg, }, h, h}-Y_{i}^{\text {neg,c }}\right)\right. \\
\left.-\left(Y_{i}^{\text {exp }, v, h}-Y_{i}^{\text {exp }, c}\right)\right]\end{array}$} & 0.00 & -0.02 & 0.03 & -0.01 & -0.04 & 0.03 \\
\hline & $(0.03)$ & $(0.03)$ & $(0.03)$ & $(0.03)$ & $(0.03)$ & $(0.03)$ \\
\hline \multirow{2}{*}{$\begin{array}{l}E\left[\left(Y_{i}^{\text {neg,i,h }}-Y_{i}^{\text {neg,c }}\right)\right. \\
\left.-\left(Y_{i}^{\text {exp }, i, h}-Y_{i}^{\text {exp }, c}\right)\right]\end{array}$} & -0.00 & 0.03 & -0.01 & 0.01 & 0.02 & -0.00 \\
\hline & $(0.03)$ & $(0.03)$ & $(0.02)$ & $(0.03)$ & $(0.03)$ & $(0.02)$ \\
\hline \multirow{2}{*}{$\begin{array}{l}\text { Observations } \\
\text { R-squared }\end{array}$} & 3,191 & 3,191 & 3,191 & 3,191 & 3,191 & 3,191 \\
\hline & 0.01 & 0.01 & 0.01 & 0.00 & 0.01 & 0.01 \\
\hline$E\left(Y_{i}^{d e l, u, h}-Y_{i}^{e x p, u, h}\right)$ & $\begin{array}{c}0.00 \\
(0.02)\end{array}$ & $\begin{array}{c}-0.05^{* *} \\
(0.02)\end{array}$ & $\begin{array}{l}-0.01 \\
(0.02)\end{array}$ & $\begin{array}{c}0.01 \\
(0.02)\end{array}$ & $\begin{array}{c}-0.08^{* * *} \\
(0.02)\end{array}$ & $\begin{array}{l}-0.02 \\
(0.02)\end{array}$ \\
\hline \multirow{2}{*}{$E\left(Y_{i}^{n e g, v, h}-Y_{i}^{e x p, v, h}\right)$} & $-0.03^{*}$ & $-0.04 *$ & -0.02 & $-0.03^{*}$ & $-0.04 *$ & -0.01 \\
\hline & $(0.02)$ & $(0.02)$ & $(0.02)$ & $(0.02)$ & $(0.02)$ & $(0.02)$ \\
\hline \multirow{2}{*}{$E\left(Y_{i}^{n e g, i, h}-Y_{i}^{e x p, i, h}\right)$} & $-0.04^{*}$ & 0.00 & $-0.06 * *$ & -0.01 & 0.01 & $-0.05 * *$ \\
\hline & $(0.02)$ & $(0.02)$ & $(0.02)$ & $(0.02)$ & $(0.02)$ & $(0.02)$ \\
\hline
\end{tabular}




\section{Discussion and Concluding Remarks}

\subsection{Description of the main findings}

4 In this article, we assess alternative strategies to increase legitimacy of mitigation policies for

5 Covid19. As the pandemic is on its way to affect all countries, we are witnessing the following

6 situation: new countries and areas are likely to become the focus of the pandemic, some countries

7 are in the transition between lockdown and post lockdown, and some areas are fighting to avoid

8 a second outburst. In the three cases, government are fighting with behavioral fatigue, because

9 the pandemic has already produced a strong negative shock, this situation has been enduring for

10 month, and the uncertainty has increase frustration. Notice that this problem was anticipated by

11 a review of the evidence from previous quarantine (Brooks et al. 2020). Legitimacy is key in this

12 endeavor and substantive legitimacy in particular, this is because procedural legitimacy, which is

13 the standard way through which this is achieved in democratic states is less strong as an argument

14 given that governments recurred to emergency power almost everywhere.

15 We focus on three different policies, namely social isolation, tracing, and testing, and we

16 present them to participants with three different arguments in support, asking subjects to rate

17 them. Arguments are expert endorsement, civil society endorsement, and negotiation between

18 opposing interests. We induce exogenous variations via priming, to assess if presence of conflicts

19 of values or interests, or high uncertainty affect the way in which legitimacy is built. We found 20 that expert endorsement is preferred under consensual domain, coherently with our hypotheses.

21 Contrary to our pre-registered hypotheses, we found that conflicts do not increase support for 22 alternative arguments.

24 5.2. Discussion of the findings in the light of the literature 
This paper contributes to a fast-growing literature on how to design policies which anticipate

2 the behavioral response by citizens. Some scholars suggest taking a behavioral angle similar to a

3 standard Nudge approach (Lunn et al. 2020; Van Bavel et al. 2020; Halpern et al. 2020): this

4 implies using a combination of debiasing and counterbiasing strategies (Shafir 2013) to promote

5 compliance. Other proposed a social norm approach: social norms are rule of conduct which

6 are contingent to certain situations and whose compliance is causally affected by empirical

7 expectations on what other people do, and normative expectations on what other people think

8 ought to be done (Bicchieri, 2006; 2016). In a recent paper, Bicchieri et al. (2020) elicit the

9 willingness to comply with individual measures to prevent contagion in 9 countries, finding that

10 expectations matter and that belief in science is an important mediator.

11 Although our approach is similar to the latter, the former could be an important complement

12 to ours because behaviorally designed interventions may be used to improve upon the arguments

13 that can increase legitimacy. As regard to the approach of social norms, although we share the

14 interest in how to increase preference to comply, we claim that legitimacy is a channel through

15 which citizens prefer to adopt a behavior, which is alternative to conditional preferences: in

16 Bicchieri (2016)'s taxonomy, preference for legitimacy can be conceptualized as independent

17 normative preferences for compliance.

18 Obviously, other works have been investigating the issue of legitimacy of institutions in time 19 of Covid19, for instance, the multi-country (non-representative) sample study by Fetzer et al.

20 (2020) and the policy paper by Khemani (2020) in the context of the World Bank. We 21 complement that work by testing specific hypotheses.

22 More broadly, it can be argued that our work is related with the literature on cooperation in 23 social dilemmas. A social dilemma (Dawes, 19980) is an interaction where the individual 
1 incentive to be selfish paves the way to a less efficient social outcome, while generalized

2 compliance could achieve the social optimum. A discussion of the literature on cooperation in

3 social dilemma and the application to the Covid19 is in Johnson et al. (2020). As for the case of

4 social norms above, we argue that legitimacy is a way to promote unconditional cooperation and

5 is potentially complementary with other policies to change beliefs and promote conditional

6 cooperation, which is usually the focus of this alternative literature.

7 Additionally, the results of this paper can be discussed in the light of the literature of risk

8 communication. A recent paper by Balog-Way and McComas (2020) highlights three themes in

9 risk communication which are important for the pandemic crisis: trust, trade-offs, and

10 preparedness. We argue that our results are relevant for that debate since legitimacy is the ground

11 on which vertical trust (i.e. towards institutions) can endure, since our arguments based on trade-

12 off (negotiated conflict) prove to be less effective, and since preparedness is a powerful tool to

13 increase legitimacy (South Korea has been a case in point). Balog-Way and McComas (2020)

14 raise the question of how much transparency should be allowed in this matter. Although our

15 results suggest that $e x$ authoritate works, we still aim to be cautious, given that a recent study

16 detected Social Desirability Bias in reporting concerns for economic consequences of harsh

17 mitigation strategies which have been recommended by experts (Codagnone et al. 2020).

18 The results can be informative as well for the literature on control policy, e.g. for addiction 19 and other health risk behavior (Daoust, 2020; Wall, 2013; Halperin and Rigotti, 2010; Passik et 20 al 2008, Seto 1995). In general, this literature suggests that risk perception drives compliance. As 21 we said above, our results complement the findings that behavioral biases and conditional 22 preferences may drive adoption of a rule of conduct. 
We believe that since our messages are essentially a discussion about sources, this paper

2 contributes to the ongoing discussion on fake news online and in the domain of Covid19 in

3 particular. It is interesting to note that expert endorsement does work, but in this context the

4 argument is based on the source and not the content. As a result, the current paper seems to 5 conflict with Dias et al. (2020), where the source does not affect susceptibility to

6 (mis)information. Given the increasing role of experts in decision-making in this contingency, it

7 may reflect yet another way in which polarization drives behavioral response (Grossman et al. 8 2020).

9 This paper also contributes to the literature on the role of experts (Saltelli et al. 2020; Saltelli 10 and DiFiore, 2020; Bogliacino et al. 2019; Cartwright and Hardie 2015; Hoppe 1999). We look

11 at how using expert endorsement, with respect to alternative arguments, can shape the perceived

12 legitimacy of decisions adopted by the government. In the contingency of the pandemics, some 13 experts have been taking on increasing political responsibility, as in the case of the work by the 14 Imperial College which has suggested to be responsible for decisions taken in multiple countries. 15 Although criticized because experts are not elected and lack a specifically designed set of checks 16 and balances, they have been defended on the ground of the emergency. According to our 17 results, experts do matter in terms of effectiveness, although the specific timing of data 18 collection, where experts' role was at the zenith may have exaggerated the impact and explain 19 why we fail to reject some of the hypotheses. In general, our results provide further evidence on 20 the debate over evidence-based policy (John and Stoker, 2019), strengthening the support for 21 this strategy but extending it to a domain, communication, which was overlooked by the 22 traditional debate. 
2 This article is based on a representative sample in three countries (Italy, Spain, and the UK), 3 with data collected in the period where they were recovering from a very heavy death toll. This

4 suggests that our results are externally valid for measuring the approval of policy options for 5 mitigation and for the approval of the arguments and communication strategies.

6 The analysis of the robustness of the results to different framing of the discourse is another 7 strength of this work, and a novelty in the literature.

8 A potential critique concerns our outcome variables and their self-reported nature, which can 9 be subject to Social Desirability Bias. Recently, Daoust et al. (2020) suggest a technique to lower 10 the potential negative consequences of overreporting compliance in surveys over Covid19 (face11 saving). Given that our research design relies on randomization and we have no particular reason 12 to believe that SDB interacts with treatment assignment, our results should be robust to this 13 issue.

14 Another critique could be that we did not explore messages that were more related with the 15 reference group of participants, this has proven to be more efficacious in terms of compliance 16 to norms (Bicchieri et al. 2019). In fact, there are many other possible arguments that could be 17 explored to complement our results, but we focused on the source of legitimacy for its relevance 18 in the current policy debate. A similar discussion could be raised around the use of pure text 19 instead of images: as we said above, this opens the toolbox of using Nudges to improve 20 legitimacy, but this was beyond the scope of this article.

21 Finally, it is possible that the priming, being a very mild manipulation, contrasted with the 22 overflow of Covid19 related information and emotions and was not capable of providing enough 
1 variation. Stronger manipulations were impracticable in online survey, but this may suggest that

2 our results provide a lower bound of the overall effect.

3

4 


\section{References}

2 Akerlof, G. A. (1980). A Theory of Social Custom, of Which Unemployment May be One

3 Consequence. The Quarterly Journal of Economics, 94(4), 749. doi:10.2307/1885667

4 Bagchi, K., Bannan, C., Bradford, S., Hurlburt, H., Sarkesian, L., Schulman, R., \& Stager, J. 5 (2020). Digital Tools for COVID-19 Contact Tracing: Identifying and Mitigating the Equity, 6 Privacy, and Civil Liberties Concerns. July 2. White Paper. Center for Ethics. Harvard University. 7 https://ethics.harvard.edu/files/center-for-ethics/files/22civilliberties.pdf

8 Balog-Way, DHP, McComas, KA, (2020) COVID-19: Reflections on trust, tradeoffs, and 9 preparedness, Journal of Risk Research, DOI: 10.1080/13669877.2020.1758192

10 Barari, S., Caria, S, Davola, A, Falco, P, Fetzer, T, Fiorin, S, Hensel, L, Ivchenko, A, Jachimowicz, 11 J King, G Kraft-Todd, G, Ledda, A, MacLennan, M, Mutoi, L, Pagani, M, Reutskaja, E, 12 Raimondi Slepoi, F (2020). "Evaluating COVID-19 Public Health Messaging in Italy: Self13 Reported Compliance and Growing Mental Health Concerns." medRxiv

14 Barton, C. M., Alberti, M., Ames, D., Atkinson, J.-A., Bales, J., Burke, E., ... Tucker, G. (2020). 15 Call for transparency of COVID-19 models. Science, 368(6490), 482.2-483. 16 doi:10.1126/science.abb8637

17 Béland, D., Carstensen, M. B., \& Seabrooke, L. (2016). Ideas, Political Power and Public Policy. 18 Journal of European Public Policy, 23(3), 315-317. doi: 10.1080/13501763.2015.112216

19 Benford, R., \& Snow, D. (2000). Framing Processes and Social Movements: An Overview and 20 Assessment. Annual Review of Sociology, 26, 611-639. Retrieved from 21 http://www.jstor.org/stable/223459

22 Bicchieri, C, Fatas, E, Aldama, A, Casas, A, Deshpande, I, Lauro, M, Parilli, C, Spohn, M, Pereira, 23 P and Wen, R (2020) A New Social Norm: Trust in Science Compliance with Public Health 24 Guidelines in a Cross-Country Survey Experiment, mimeo

25 Bicchieri, C., Dimant, E., Gächter, S., \& Nosenzo, D. (2019). Observability, social proximity, 26 and the erosion of norm compliance. Working paper. Available at SSRN: https 27 ://ssrn.com/abstr act=33550 28.

28 Bicchieri, Norms in the wild: How to diagnose, measure, and change social norms, Oxford 29 University Press, 2016.

30 Bicchieri, C. (2006). The grammar of society: The nature and dynamics of social norms. Cambridge 31 University Press.

32 Bogliacino, F., Codagnone, C., \& Veltri, G. A. (2015). The Behavioural Turn in Consumer 33 Policy: Perspectives and Clarifications. Intereconomics. doi:10.2139/ssrn.2585670

34 Bogliacino, F., Codagnone, C., \& Veltri, G. A. (2019). Citizens-experts' interactions under 35 different institutional arrangements: assessing the role of uncertainty, interests, and values. 36 Journal of Institutional Economics, 1-19. doi:10.1017/s1744137419000067 
Bogliacino, F., Villanueva, F. L., codagnone, c., Charris, R. A., Gómez, C. E., Folkvord, F., Liva, G, Veltri, GA, Reith, G. (2020, a). Longitudinal study on behavioral, psychological, socioeconomic effects induced by the exposure to CoViD-19, by government measures, and by communication strategies in three countries: Italy, Spain, and United Kingdom. https://doi.org/10.17605/OSF.IO/6XWE8

Bogliacino, F., Villanueva, F. L., Codagnone, C, Charris, R. A., Gómez, C. E., Folkvord, F., Liva, G, Veltri, GA, Reith, G. (2020b). Longitudinal study on behavioral, psychological, socioeconomic effects induced by the exposure to CoViD-19, by government measures, and by communication strategies in three countries: Italy, Spain, and United Kingdom. https://doi.org/10.17605/OSF.IO/TBYS6

11 Brooks, S., Webster, R., Smith, L., Woodland, L., Wessely, S., Greenberg, N., James, G. (2020). 12 The psychological impact of quarantine and how to reduce it- rapid review of the evidence. 13 Department of Psychological Medicine, King's College, S0140-6736(20)30460-8. Advance online publication. https://doi.org/10.1016/S0140-6736(20)30460-8

Campbell, D. T. (1969). Reforms as experiments. American Psychologist, 24(4), 409-429. doi:10.1037/h0027982

Carrozza, C. (2014). Democratizing Expertise and Environmental Governance: Different Approaches to the Politics of Science and their Relevance for Policy Analysis. Journal of Environmental Policy \& Planning, 17(1), 108-126. doi:10.1080/1523908x.2014.914894

Carstensen, M., \& Schmidt, V. (2016). Power through, over and in ideas: conceptualizing ideational power in discursive institutionalism. Journal of European Public Policy, 23(3), 318-337.

Cartwright, N., \& Hardie, J. Evidence-Based Policy: A Practical Guide to Doing It Better (New York, 2012; pubd online Feb. 2015). Oxford Scholarship Online, 24 http://dx.doi.org/10.1093/acprof:osobl/9780199841608.001.0001

Chakraborty, A., Ghosh, P., \& Roy, J. (2020). Expert-Captured Democracies. American Economic Review, 110(6), 1713-1751. doi:10.1257/aer.20181396

Chudik, A., Pesaran, M., \& Rebucci, A. (2020). Voluntary and Mandatory Social Distancing: 28 Evidence on COVID-19 Exposure Rates from Chinese Provinces and Selected Countries, 29 CEPR Discussion Paper 14646.

30 Codagnone, C, Bogliacino, F., Gómez, C. E., Charris, R. A., Montealegre, F., Liva, G., Lupiáñez31 Villanueva, F, Folkvord, F, Veltri, G. A., (2020, May 30). Assessing concerns for the economic 32 consequence of the COVID-19 response and mental health problems associated with economic 33 vulnerability and negative economic shock in Italy, Spain, and the United Kingdom. 34 https://doi.org/10.31235/osf.io/x9m36

35 Crawford, V. P., \& Sobel, J. (1982). Strategic Information Transmission. Econometrica, 50(6), 36 1431. doi:10.2307/1913390

37 Daoust, J-F. 2020. "Elderly People and Responses to COVID-19 in 27 Countries.” PloS One. 
Daoust, JF, R. Nadeau, R. Dassonneville, E. Lachapelle, É. Bélanger, J. Savoie and v. d. L. C. , 2 "How to survey citizens' compliance with COVID-19 public health measures? Evidence from 3 three survey experiments," Journal of Experimental Political Science, 2020.

4 Dawes, R. M. (1980). Social dilemmas. Annual Review of Psychology, 31, 169-193.

Dehue, T. (2002), «A Dutch treat: randomized controlled experimentation and the case of heroin-maintenance in the Netherlands», History of the Human Sciences, 15(2), pp. 75-98

Dias, N., Pennycook, G. \& Rand, D. G. (2020). Emphasizing publishers does not effectively reduce susceptibility to misinformation on social media. The Harvard Kennedy School (HKS) Misinformation Review

Entman, R. (1993). Framing: Toward Clarification of a Fractured Paradigm. Journal of Communication, 43(4), 51-58.

Fehr, E., \& Gächter, S. (2000). Fairness and Retaliation: The Economics of Reciprocity. The 13 Journal of Economic Perspectives, 14(3), 159-181. Retrieved July 6, 2020, from 14 www.jstor.org/stable/2646924

Fehr, E., \& Gächter, S. (1998). Reciprocity and economics: The economic implications of Homo Reciprocans. European Economic Review, 42(3-5), 845-859. doi:10.1016/s0014-2921(97)00131-1

Fehr, E., Kirchsteiger, G., \& Riedl, A. (1998). Gift exchange and reciprocity in competitive experimental markets. European Economic Review, 42(1), 1-34. doi:10.1016/s00142921 (96)00051-7 Fehr, E. (2009). On The Economics and Biology of Trust. Journal of the European Economic Association, 7(2-3), 235-266. doi:10.1162/jeea.2009.7.2-3.235

Fetzer, T, M. Witte, L. Hensel, J. Jachimowicz, J. Haushofer, A. Ivchenko, S. Caria, E. Reutskaja, C. Roth, S. Fiorin, M. Gómez, G. Kraft-Todd, F. Götz, E. Yoeli, , "Global behaviors and perceptions in the COVID-19 pandemic," Working Paper, 2020

Funtowicz, S. and J. Ravetz (2018), 'Post-normal Science. In Castree, N., In Hulme, M., \& In Proctor, J. D. (2018). Companion to environmental studies, London and New York, Routledge.

Grossman, G, Soojong Kim, Jonah M. Rexer, Harsha Thirumurthy (2020) Political partisanship influences behavioral responses to governors' recommendations for COVID-19 prevention in the United States. Proceedings of the National Academy of Sciences, 117 (39) 24144-24153

Gueron, J. M. (2017). The Politics and Practice of Social Experiments. Handbook of Economic Field Experiments, 27-69. doi:10.1016/bs.hefe.2016.11.001

Halperin AC, MPH \& Rigotti NA (2003) US Public Universities' Compliance With Recommended Tobacco-Control Policies, Journal of American College Health, 51:5, 181-188, DOI: $10.1080 / 07448480309596349$

Halpern, SD, R. D. Truog and F. G. Miller, "Cognitive Bias and Public Health Policy During the COVID-19 Pandemic,", JAMA

Hoppe, R. (1999) Policy analysis, science and politics: From speaking truth to power to making sense together, Science and Public Policy, 26(3): 201-10. 
Ioannidis, J. P. A. (2020). Coronavirus disease 2019: the harms of exaggerated information and non-evidence-based measures. European Journal of Clinical Investigation, e13222. 3 doi:10.1111/eci.13222

4 John, P, Stoker, G (2019) Rethinking the role of experts and expertise in behavioural public 5 policy, Policy \& Politics, 47(2): 209-25

6 Johnson, T, Dawes, CT, Fowler, JH, Smirnov, O (2020) Slowing COVID-19 transmission as a 7 social dilemma: Lessons for government officials from interdisciplinary research on cooperation, 8 Journal of Behavioral Public Administration Vol 3(1)

9 Jones, B. D., Thomas, H. F., \& Wolfe, M. (2014). Policy Bubbles. Policy Studies Journal, 42(1), 14610 171. doi:10.1111/psj.12046

11 Kearns, C.E., Schmidt, L.A. e Glantz, S.A. (2016), Sugar Industry and Coronary Heart Disease 12 Research A Historical Analysis of Internal Industry Documents, JAMA Internal Medicine, 13 176(11): 1680-1685, doi:10.1001/jamainternmed.2016.5394.

14 Khemani, S "An Opportunity to Build Legitimacy and Trust in Public Institutions in the Time 15 of COVID-19.," World Bank Research and Policy Briefs, no. 32, 2020

16 Klandermans, B. (1997). The Social Psychology of Protest. Oxford: Blackwell

17 Kuypers, J. (2010). Framing Analysis as a Rhetorical Process. In P. D'Angelo \& J. Kuypers (Eds.), 18 Doing News Framing Analysis (pp. 286-311). New York: Routledge.

19 Lazear, E. P., Shaw, K. L., \& Stanton, C. T. (2018). Who Gets Hired? The Importance of 20 Competition among Applicants. Journal of Labor Economics, 36(S1), S133-S181. 21 doi:10.1086/694908

22 Lunn, P.D., Belton, C.A., Lavin, C., McGowan, F.P., Timmons, S., \& Robertson, D.A. (2020). 23 Using behavioral science to help fight the coronavirus. Journal of Behavioral Public 24 Administration, 3(1), 1-35

25 Maor, M. (2014). Policy persistence, risk estimation and policy underreaction. Policy Sciences, 26 47(4),425-443.

27 Maor, M. (2016). Emotion-driven negative policy bubbles. Policy Sciences, 49(2), 191-210. 28 doi:10.1007/s11077-015-9228-7

29 Melnick, E. R., \& Ioannidis, J. P. A. (2020). Should governments continue lockdown to slow the 30 spread of covid-19? BMJ, m1924. doi:10.1136/bmj.m1924

31 Mügge, D. (2016). Studying macroeconomic indicators as powerful ideas. Journal of European 32 Public Policy, 23(3), 410-427.

33 Olson, M. (1977). The logic of collective action: Public goods and the theory of groups. 34 Cambridge, Mass: Harvard University Press.

35 Passik, SD, Kirsh, KL, Casper, D (2008) Addiction-Related Assessment Tools and Pain 36 Management: Instruments for Screening, Treatment Planning, and Monitoring Compliance Pain 
1 Medicine, Volume 9, Issue suppl_2, Pages S145-S166, https://doi.org/10.1111/j.1526-

$2 \quad 4637.2008 .00486 . x$

3 Pielke, R. (2007). The honest broker. Making sense of science in policy and politics. Cambridge:

4 Cambridge University Press.

5 Posner, R. (1999) An economic approach to the law of evidence. Stanford Law Review, 51(6): 1477-

61546

7 Romer, P. (2020, April 23). Roadmap to responsibly Reopen America. Retrieved from

8 https://paulromer.net/roadmap-to-reopen-america/

9 Saltelli, A, Di Fiore, M, 2020, From sociology of quantification to ethics of quantification, 10 Humanities and Social Sciences Communications, https://doi.org/10.1057/s41599-020-00557110.

12 Saltelli, A, G. Bammer, I. Bruno, E. Charters, M. Di Fiore, E. Didier, W. Nelson Espeland, J. 13 Kay, S. Lo Piano, D. Mayo, R.J. Pielke, T. Portaluri, T.M. Porter, A. Puy, I. Rafols, J.R. Ravetz, 14 E. Reinert, D. Sarewitz, P.B. Stark, A. Stirling, P. van der Sluijs, Jeroen P. Vineis, Five ways to 15 ensure that models serve society: a manifesto, Nature 582 (2020) 482-484.

16 Seabrooke, L., \& Wigan, D. (2016). Powering ideas through expertise: professionals in global tax 17 battles. Journal of European Public Policy, 23(3), 357-374.

18 Seto, WH (1995) Staff compliance with infection control practices: application of behavioural sciences. Journal of Hospital Infection Volume 30, Supplement, June 1995, Pages 107-115

Shafir, E (2013) The behavioral foundations of public policy. Princeton University Press

Shen, C., Taleb, N., \& Bar-Yam, Y. (2020). Review of Ferguson et al "Impact of nonpharmaceutical interventions...", New England Complex Systems Institute. Available at https://necsi.edu/review-of-ferguson-et-al-impact-of-non-pharmaceutical-interventions

24 Snow, D., \& Benford, R. (1988). Ideology, frame resonance, and participant mobilization. 25 International Social Movement Research, 1, 197-217.

26 Snow, D., Rochford, E., Worden, S., \& Benford, R. (1986). Frame Alignment Processes, 27 Micromobilization, and Movement Participation. American Sociological Review, 51(4), 464-481. 28 doi:10.2307/2095581

29 Strassheim, H., \& Kettunen, P. (2014). When does evidence-based policy turn into policy-based 30 evidence? Configurations, contexts and mechanisms. Evidence \& Policy: A Journal of Research, 31 Debate and Practice, 10(2), 259-277. doi:10.1332/174426514x13990433991320

32 Taipale, J., Romer, P., \& Linnarsson, S. (2020 preprint). Population-scale testing can suppress 33 the spread of COVID-19. medRxiv. https://doi.org/10.1101/2020.04.27.20078329

34 Tversky, A., \& Kahneman, D. (1981). The framing of decisions and the psychology of choice. 35 Science, 211(4481), 453. from 36 http://science.sciencemag.org/content/211/4481/453.abstract 
1 Thibaut, J.W. and Walker, L. (1975) Procedural Justice: A Psychological Analysis. L. Erlbaum

2 Associates, Hillsdale.

3 Tyler, T. R. (2006). Psychological Perspectives on Legitimacy and Legitimation. Annual Review of

4 Psychology, 57(1), 375-400. doi:10.1146/annurev.psych.57.102904.190038

5 Tyler TR. (2001). A psychological perspective on the legitimacy of authorities and institutions.

6 See Jost \& Major 2001, pp. 416-36

7 Tyler, T. R. (2011). Trust and legitimacy: Policing in the USA and Europe. European Journal of

8 Criminology, 8(4), 254-266. doi:10.1177/1477370811411462

9 Van Bavel, JJ K. Baicker, P. S. Boggio, V. Capraro, A. Cichocka, M. Cikara, M. J. Crockett, A. J. 10 Crum, K. M. Douglas, J. N. Druckman, J. Drury, O. Dube, N. Ellemers, E. J. Finkel, J. H. 11 Fowler, M. Gelfand, S. Han, S. A. Haslam, J. Jetten, S. Kitayama, D. Mobbs, L. E. Napper, D. 12 J. Packer, G. Pennycook, E. Peters, R. E. Petty, D. G. Rand, S. D. Reicher, S. Schnall, A. Shariff, 13 L. J. Skitka, S. S. Smith, C. R. Sunstein, N. Tabri, J. A. Tucker, S. van der Linden, P. van Lange, 14 K. A. Weeden, M J. A. Wohl, J. Zaki, S. R. Zion \& R. Willer., "Using social and behavioural 15 science to support COVID19 pandemic response," Nature Human Behaviour, pp. 1-12, 2020.

16 Wall, JD, Prashant Palvia \& Paul Benjamin Lowry (2013) Control-Related Motivations and 17 Information Security Policy Compliance: The Role of Autonomy and Efficacy, Journal of 18 Information Privacy and Security, 9:4, 52-79, DOI: 10.1080/15536548.2013.10845690

19 Wallner, J. (2008). Legitimacy and Public Policy: Seeing Beyond Effectiveness, Efficiency, and 20 Performance. Policy Studies Journal, 36(3), 421-443. doi:10.1111/j.1541-0072.2008.00275.x

21 Zhuravskaya, E., Petrova, M., \& Enikolopov, R. (2020). Political Effects of the Internet and 22 Social Media. Annual Review of Economics, 12(1). doi:10.1146/annurev-economics-081919-050239 


\section{Annex I. Section I. The experimental protocol}

"Before moving to the questions, we ask you to read the following statement. Consider that the following statement has been elaborated based on different information, e.g. sources from official government, scientific or other media sources in different countries. We made sure that we do not misreport the original source or add interpretations."

- [High uncertainty] "A famous epidemiologist and statistician claimed that the data currently collected on COVID-19 pandemic are unreliable, especially those concerning infections and deaths because of limited testing. For instance, we may be missing the right number of infections by an order of magnitude of three or 300 .

While an international organization reports a fatality rate of $3.4 \%$ (i.e., number of deaths divided by the number of infected persons) frightening the public, the expert affirms that this may be meaningless due to the unreliability of the data used to calculate this rate.

- [Low uncertainty] "A prediction published in a widely read US newspaper put between 160 and 214 million the number of people that could be infected with COVID-19 in the United States in course of months or even a year.

Between 2.4 million and 21 million could be possibly hospitalized with a serious risk to the national health system.

The supply of ventilators may be short of the critical cases by an order of ten (i.e. every ten patients there may be one ventilator). As a result, up to 1.7 million people could die."

- $\quad$ V alue conflict] "According to information reported by newspapers, one avenue to cope with the spread of the COVID-19 is to use technology to track outbreaks of infection by matching information about people and their movements. Scientists from prestigious universities have already been working on these algorithms that use GPS and Bluetooth trails.

The initiative has raised concern about privacy, since it is not clear how the tracking technology access the information about the user location, and also because the tracked information could be available to health and government authorities without user consent".

- $\quad$ V alue consensus] "According to information reported by newspapers, one avenue to cope with the spread of the COVID-19 is to use technology to track outbreaks of infection by matching information about people and their movements. Scientists from prestigious universities have already been working on these algorithms that use GPS and Bluetooth trails.

This solution raised hopes that people exposed to the virus can be alerted and seek treatment, thus, lowering the risk of exposures in public spaces such as public transport. In addition, this solution may enable real-time information for optimizing interventions".

- [Low rents] "The COVID-19 pandemic is posing governments with the dilemma of whether they should prioritize public health over the economy. For example, religious 
authorities point out that if the population is not protected with measures such as quarantine, we will attend a genocide.

This view is echoed by the majority of scientists and prominent doctors, who agree that restrictions such as quarantines are for the common good, despite their economic consequences. So, there is consensus that it is more important to protect health than the economy."

- [High rents] "During the COVID-19 crisis some distinguished personalities have affirmed that the economic consequences cannot be underestimated.

For example, a well-recognized economist wrote recently in a widely circulated newspaper that the strategies adopted to cope separately with the health and economic crisis are contradictory and may lead to long terms disaster.

While isolation and social distancing aim at saving lives, they lead to a halt of the economic system, so that the unemployment rate may skyrocket, and households see their savings and current earnings severely affected. Similar opinions are shared across the political spectrum."

1) We will now ask you some questions about the following policy in response to COVID-19 (that has been already adopted or may be adopted in the future). Please focus your attention on its description, as well as on the arguments and motivations behind it.

Policy $\mathbf{Q}$ “This policy requires restriction of activities and mobility for people who are not ill but who may be exposed to infectious agents or to the disease. This with the purpose of early detecting and monitoring the disease, as well as reducing at minimum social contact to slow down the contagion. According to this policy, people may be allowed to leave their house but only when it is absolutely necessary: for example, for medical treatments, purchasing groceries or another emergency."

The policy was justified with the following argument [show only one, according to experimental condition]

a. Experts were consulted and argue that this policy is a good measure to stop the spread of the disease based on studies and data taken from previous epidemics, and pandemics. According to the estimates, contagion in the community would be significantly reduced, if the majority of the households comply with the policy.

b. The government has consulted with the citizens on this policy and participants argue that, although the economic cost will be extraordinary, after deliberation they agree on implementing such a policy because in this moment health is more important than the economy.

c. The government has listened to different arguments, from both scientific source and civil society (e.g. citizens, NGOs, industry associations and trade unions). It has been recognized that experts have a reasonable estimation of the negative consequences of putting the health system under critical stress, but they underestimate the economic consequences. At the opposite, representatives of the civil society have claimed that the economic cost will be disproportionate. 
The government has decided, weighting these opposing arguments, for the time being to adopt this policy as a temporary measure.

Q1 We now ask you to think about the policy and answer honestly reporting your level of agreement with the following statement. Answer on a scale from 1 to 7, where 1 stands for "I don't agree at all" and 7 to "I completely agree". You can also use the values in between to indicate where you fall on the scale.

$7 \quad$ I would support this policy if proposed to be implemented in my country

Q2 We now ask you to think at the justification for the adoption of the policy and answer honestly reporting your level of agreement with the following statement. Answer on a scale from 1 to 7 , where 1 stands for "I don't agree at all" and 7 to "I completely agree". You can also use the values in between to indicate where you fall on the scale.

I think that this is a solid argument to convince me to support this policy

\section{Slider from 1 to 7}

Q3 We now ask you to think at the opportunity to use this justification as a communication strategy to persuade citizens to support the policy. Answer honestly reporting your level of agreement with the following statement. Answer on a scale from 1 to 7 , where 1 stands for "I don't agree at all" and 7 to "I completely agree". You can also use the values in between to indicate where you fall on the scale.

I would like this message to be part of the communication strategy of the government

\section{Slider from 1 to 7}

2) We will now ask you some questions about the following policy in response to COVID-19 (that has been already adopted or may be adopted in the future). Please focus your attention on its description, as well as on the arguments and motivations behind it.

Policy T: "This policy is based on enabling an App that helps track if the user had contact with an infected person. All users must scan a QR code with the use of some standard application. People that appear to be at risk are then advised to stay at home. There are three possible results from the app: if the person gets green, that means he/she is healthy; yellow means the person should do a 7-day quarantine; red means a 14-day quarantine. All the data is available to the government."

The policy was justified with the following argument [show only one, according to experimental condition]

a. Experts were consulted and argued that the contact tracing through an app is a good measure to control the spread of the disease, based on the positive outcomes of this measure in other countries. According to the experts, the 
implementation of this measure would significantly reduce the contagion, if the majority of the population adopt the App and use it regularly.

b. The government has consulted with the citizens on this policy and participants argue that, although the threat in terms of freedom and personal rights will be large, after deliberation they agree on implementing such a policy because in this moment health is more important than freedom.

c. The government has listened to different arguments, from both scientific sources and the civil society (e.g. citizens, NGOs, industry associations, and trade unions). It has been recognized that tech experts have a reasonable estimation of the accuracy of the app, but they underestimate the privacy issue. At the opposite, civil society is focused on raising the risk of privacy violations and threat to citizens' rights. The government has decided, weighting these opposing arguments, for the time being to adopt the technological solution as a temporary measure.

Q1 We now ask you to think at the policy and answer honestly reporting your level of agreement with the following statement. Answer on a scale from 1 to 7 , where 1 stands for "I don't agree at all" and 7 to "I completely agree". You can also use the values in between to indicate where you fall on the scale.

I would support this policy if proposed to be implemented in my country

\section{Slider from 1 to 7}

Q2 We now ask you to think about the justification for the adoption of the policy and answer honestly reporting your level of agreement with the following statement. Answer on a scale from 1 to 7 , where 1 stands for "I don't agree at all" and 7 to "I completely agree". You can also use the values in between to indicate where you fall on the scale.

I think that this is a solid argument to convince me to adopt this policy

Slider from 1 to 7

Q3 We now ask you to think at the opportunity to use this justification as a communication strategy to persuade citizens to support the policy. Answer honestly reporting your level of agreement with the following statement. Answer on a scale from 1 to 7 , where 1 stands for "I don't agree at all" and 7 to "I completely agree". You can also use the values in between to indicate where you fall on the scale.

I would like this message to be part of the communication strategy of the government

Slider from 1 to 7

3) We will now ask you some questions about the following policy in response to COVID-19 (that has been already adopted or may be adopted in the future). Please focus your attention on its description, as well as on the arguments and motivations behind it. 
Policy D: "The aim of this measure is to identify people who have already been infected with COVID-19. In particular, it aims to ease quarantine measures for those who have already recovered from the virus, so that they can return to work and their normal activities. This measure is based on a large-scale testing method. The test is not $100 \%$ accurate and does not guarantee immunity".

\section{The policy was justified with the following argument [show only one, according to experimental} condition]

a. Experts were consulted and argued that the use these tests is a good measure to cope with the new phase of the pandemic, based on the results of laboratory experiments. According to the estimates, the number of people already infected is much larger than official numbers and these people may be already immune. According to the experts, the implementation of this measure would significantly reduce the negative consequences on the economy, if the majority of the population get tested and followed the prescription to return to work if cleared.

b. The government has consulted with the citizens this policy and participants argue that although this could be extremely risky since these tests are not a proof of immunity, after deliberation they agree on implementing such a policy because in this moment putting the economy first is a necessary step ahead.

c. The government has listened to different arguments, from both scientific source and the civil society (e.g. citizens, NGOs, industry associations and trade unions). It has been recognized that experts have a reasonable confidence on the accuracy of the test, but they underestimate the risk of experimenting a reopening. At the opposite, civil society has claimed that this policy is directly exposing a large chunk of the population to incredible risk. The government has decided weighting these opposing arguments that the temporary measure will be the experimental adoption of the reopening of the economy conditional on having been tested and based on its result.

Q1 We now ask you to think at the policy and answer honestly reporting your level of agreement with the following statement. Answer on a scale from 1 to 7 , where 1 stands for "I don't agree at all" and 7 to "I completely agree". You can also use the values in between to indicate where you fall on the scale.

I would support this policy if proposed to be implemented in my country

\section{Slider from 1 to 7}

Q2 We now ask you to think at the justification for the adoption of the policy and answer honestly reporting your level of agreement with the following statement. Answer on a scale from 1 to 7, where 1 stands for "I don't agree at all" and 7 to "I completely agree". You can also use the values in between to indicate where you fall on the scale.

I think that this is a solid argument to convince me to adopt this policy

Slider from 1 to 7 
1 Q3 We now ask you to think at the opportunity to use this justification as a communication

2 strategy to persuade citizen to support the policy. Answer honestly reporting your level of 3 agreement with the following statement. Answer on a scale from 1 to 7 , where 1 stands for "I

4 don't agree at all" and 7 to "I completely agree". You can also use the values in between to 5 indicate where you fall on the scale.

6 I would like this message to be part of the communication strategy of the government

$7 \quad$ Slider from 1 to 7 